\title{
Occlusal Wear - An Age Determinant
}

Suchita $\mathrm{S}^{1}$, Pavan G Kulkarni ${ }^{2}$, Keerthi $\mathrm{M}^{3}$, Shyam Prasad Reddy $D^{4}$, Madhusudan Rao $T^{5}$

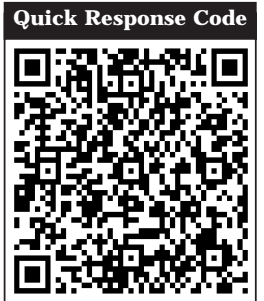

doi: 10.5866/2014.621523

${ }^{1}$ Post Graduate

${ }^{2 \& 5}$ Reader

${ }^{3 \& 4}$ Senior Lecturer

Department of Oral \& Maxillofacial Pathology,

Kamineni Institute of Dental Sciences,

Sreepuram, Narketpally,

Nalgonda (Dist), Telangana - 508254

\section{Article Info:}

Received: J anuary 8, 2014

Review Completed: February 10, 2014

Accepted: March 9, 2014

Available Online: J uly, 2014 (www.nacd.in)

(C) NAD, 2014 - All rights reserved

E mail for correspondence:

drpavangk.81@gmail.com

\begin{abstract}
:
Context: Age estimation, a sub-discipline of forensic sciences is gaining importance day by day in person identification. Not exactly atleast far possibilities should help to narrow down the search in identifying a person. Despite age estimation is of broader importance in forensic research and dinical dentistry but also a kind of social benefits in society when individuals are unaware of their age. As days pass by human body undergoes certain degenerative changes, amongst which occlusal wear of teeth is one of the physiological process which can be an age determinant.
\end{abstract}

Aims and Objectives: The aim of the present study was to estimate age of an individual by occlusal wear based Kim's scoring system.

Materials and Methods: To obtain a high level of accuracy, investigation has been confined to limited number of subjects, teeth and age group. Degree of occlusal wear was examined in maxillary and mandibular posterior teeth of 75 individuals of an age range 19 to 58 years. Scores were designated as per Kim's scoring system and age estimation was calculated by linear equation derived from regression analysis.

Results: The investigation revealed a significant positive correlation of teeth examined and age estimated with a difference of 1.52 years that of actual age. Study has al so proved theincreased wear in males than females.

Conclussion: Ultimately, an enlightening association of occlusal wear and Kim's scoring system are reliable determinants and markers in age estimation.

Key words: Forensic odontology, age estimation, ocdusal wear, Kim's scoring system.

\section{INTRODUCTION}

Teeth have been extensively used as a source of human identification especially when soft tissue cannot providereliable information. ${ }^{1}$ Teeth being the central component of the masticatory apparatus of the skull are of good sources of material for civil and medico-legal identification. In addition, the degree to which they provide resistance to damage makes them valuable for forensic investigation and research. ${ }^{2} \mathrm{~A}$ number of reports in the field of forensic odontology have dealt with estimating chronological age in humans, living or dead for legal procedures, 
to identify the victims during mass disasters and for anthropological studies. ${ }^{3,4}$ With the changing age profiles resulting in a greater number of older individuals in most countries and with improving dental health, increasing numbers of patients are presenting with extensive tooth wear. ${ }^{5}$ Wear is deterioration as a result of use. Tooth wear has existed since the beginning of humanity and in all civilizations that occurs systematically and intensively, but is considered a physiological process. In addition, it depends on many complex mechanisms, synchronous or sequential, synergetic or additive which can also often mask its true origin. In dentistry, wear is a generic term commonly used to describe phenomena of attrition (proximal and occlusal inter-dental friction), abrasion (friction with the intervention of particles) and erosion (chemical dissolution). ${ }^{6}$

There have been various methods like Schour and Massler's, Demirjian's and Gustafson's to determineage which required and included invasive procedures and confined to only few teeth of a particular age group. Although all these methods had certain drawbacks, they were modified to overcome. Amongst these various age estimating methods, Kim's system seems to be more reliable as it can be applied to wide age range without involving any invasive and time consuming procedures and is based only on the finding of occlusal wear. As occlusal wear is an age related degenerative change and could probably be a sign indicating the time period of teeth exposure to the oral cavity, it can be considered to be reliable aid in estimating age of an human. The study is undertaken with a purpose of estimating age of an individual by occlusal wear of teeth based on Kim's scoring system.

\section{MATERIALS AND METHODS}

\section{Subject Selection}

In this retrospective study 75 individuals, 39 males and 36 females grouped of known chronological age between 19 and 58 years were retrieved from the patients' files of the Department of Oral and Maxillofacial Pathology, Kamineni Institute of Dental Sciences. Inclusion criteria of the present study were sound premolars and molars and individuals with no distinct dental malocclusion. Exclusion criteria were history of any operative or prosthetic treatments, a missing tooth in premolar and molar areas, parafunctional habits (chewing, bruxism) and anterior teeth.

\section{Methodology}

Dental impression was taken with elastic cromo impression material on an impression tray of both jaws. Maxillary and mandibular dental study models were obtained of each subject. All the sixteen permanent posterior teeth were examined for tooth wear with the naked eye under good illumination. Scoring was performed based on two different criteria which are horizontal factor and vertical factor. Horizontal factor denotes the area of tooth wear and vertical factor denotes the degree of dentin exposure. To obtain an accurate score combination of both the horizontal and vertical factors were considered in the scoring system. Tooth wear score has been classified into a 0 - 8 point scale according to Kim's scoring system based on pattern, number and amount of tooth wear. (Table 1)

\section{SCORING}

All the sixteen teeth of each patient were evaluated for tooth wear and scored individually. Amongst the scores of sixteen teeth in an individual, the highest degree was designated as tooth wear score (Table 2).

The estimated age of patient was calculated by adding an intercept to the sum of numerical values obtained.

$\mathbf{Y}=\mathbf{a X}+\mathbf{b}$

- $Y=$ Estimated Age

- $\quad \mathrm{a}=$ Intercept (18.541)

- $b=$ Regression co-efficient (3.625)

- $X=$ Tooth wear score

As an illustration, $\mathrm{Y}=18.541+3.625$ (3) $=29.41$. Heretheestimated age of the patient was 29.4 years and actual age was 31 years. 


\section{RESULTS}

Means and standard deviation for individual tooth wear were calculated for males and females separately to determine the gender differences (Table3). There was a gradual increase in tooth wear score with aging in each and every tooth in both males and females ( $p<0.01$ ). Degree of tooth wear in males was higher than those in females. Regression analysis of age against tooth wear score were done to examine the relationship between age and tooth wear score (Table 4). The regression analysis showed that the degrees of correlation were relatively strong between tooth wear scores of all examined teeth (coefficient of determination, $r^{2}=$ 0.002 - 0.752). The correlation between tooth wear scores of molars ( $\left.r^{2}=0.158-0.752\right)$ was greater than premolars $\left(r^{2}=0.002-0.635\right)$. The estimated age has been calculated by adding an intercept to the sum of numerical values. Difference between estimated and actual ages is only 1.52 years. The method described here provided a high level of accuracy. (Table 3:)

Table 1: KIM's Scoring System of Toothwear

\section{SCORE}

\section{PREMOLAR}

\begin{tabular}{|c|c|c|}
\hline 0 & No visible wear & No visible wear \\
\hline 1 & IP / IL & $1 \mathrm{P} / \mathrm{IL} / 2 \mathrm{P} / 2 \mathrm{~L}$ \\
\hline 2 & $2 \mathrm{P} / 2 \mathrm{~L} / \mathrm{IS} / \mathrm{IB}$ & 3P / 3L / 4P / 4L / 1S / 1B / 2S / 2B \\
\hline 3 & $2 \mathrm{~S} / 2 \mathrm{~B}$ & $3 S / 3 B / 4 S / 4 B$ \\
\hline 4 & Wear on more than $2 / 3$ occlusal surface & \\
\hline 5 & IPC/ILC & $1 \mathrm{Pc} / \mathrm{ILC} / 2 \mathrm{PC} / 2 \mathrm{LC}$ \\
\hline 6 & $2 \mathrm{Pc} / 2 \mathrm{Lc} / \mathrm{ISC} / \mathrm{IBC}$ & $3 \mathrm{Pc} / 3 \mathrm{Lc} / 4 \mathrm{Pc} / 4 \mathrm{Lc} / \mathrm{SC} / \mathrm{IBc} / 2 \mathrm{Sc} / 2 \mathrm{BC}$ \\
\hline 7 & $2 \mathrm{Sc} / 2 \mathrm{BC}$ & $3 \mathrm{Sc} / 3 \mathrm{Bc} / 4 \mathrm{Sc} / 4 \mathrm{Bc}$ \\
\hline
\end{tabular}

$\mathrm{P}=$ Point-like wear facet less than approximately $1 \mathrm{~mm}$ in diameter (Figure 1 ).

$\mathrm{L}=\mathrm{Linear}$ wear facet less than approximately $1 \mathrm{~mm}$ in width (Figure 2).

$\mathrm{S}=$ Surface-like wear facet more than approximately $1 \mathrm{~mm}$ in diameter (Figure 3).

$\mathrm{B}=$ Band-like wear facet more than approximately $1 \mathrm{~mm}$ in width or wear facet involving more than two surfaces (Figure 4).

' $C$ '(concavity) means the wear of dentin (Figure 5).

\section{Table 2: Illustration of individual tooth scoring and the highest score} selected as tooth wear score

\begin{tabular}{cccccccccccccccccc} 
AGE & $\mathbf{1 4}$ & $\mathbf{1 5}$ & $\mathbf{1 6}$ & $\mathbf{1 7}$ & $\mathbf{2 4}$ & $\mathbf{2 5}$ & $\mathbf{2 6}$ & $\mathbf{2 7}$ & $\mathbf{3 4}$ & $\mathbf{3 5}$ & $\mathbf{3 6}$ & $\mathbf{3 7}$ & $\mathbf{4 4}$ & $\mathbf{4 5}$ & $\mathbf{4 6}$ & $\mathbf{4 7}$ & Score \\
$\mathbf{3 0}$ & 0 & 0 & 1 & 0 & 0 & 0 & 0 & 2 & 0 & 0 & $\underline{\mathbf{3}}$ & 0 & 0 & 0 & 0 & 1 & 3 \\
\hline $\mathbf{2 3}$ & $\mathbf{1}$ & 0 & 0 & 0 & 0 & 0 & 0 & 0 & 0 & 0 & $\underline{\mathbf{1}}$ & 0 & 0 & 0 & 0 & $\underline{\mathbf{1}}$ & 1 \\
\hline $\mathbf{3 5}$ & 1 & 0 & 2 & 1 & 1 & 0 & 1 & 3 & 1 & 0 & 0 & 2 & 0 & 0 & $\underline{\mathbf{5}}$ & $\underline{\mathbf{5}}$ & 5 \\
\hline $\mathbf{4 4}$ & 2 & 1 & 3 & 6 & 0 & 1 & $\underline{\mathbf{7}}$ & 2 & 0 & 0 & 5 & 0 & 0 & 3 & 3 & 1 & 7 \\
\hline $\mathbf{3 8}$ & 1 & 1 & 2 & $\underline{\mathbf{4}}$ & 1 & 2 & $\mathbf{4}$ & 3 & 1 & 1 & $\underline{\mathbf{4}}$ & $\mathbf{4}$ & 0 & 1 & 2 & $\mathbf{4}$ & 4 \\
\hline $\mathbf{4 9}$ & 1 & 1 & 4 & 6 & 1 & 1 & 4 & 5 & 1 & 1 & 6 & $\underline{\mathbf{8}}$ & 1 & 1 & 4 & $\underline{\mathbf{8}}$ & 8 \\
\hline $\mathbf{2 6}$ & 0 & 1 & 0 & 0 & 1 & 0 & 0 & $\underline{\mathbf{2}}$ & 1 & 0 & 0 & $\underline{\mathbf{2}}$ & 0 & 0 & 1 & 0 & 2 \\
\hline $\mathbf{4 0}$ & 1 & 0 & 5 & $\underline{\mathbf{6}}$ & 0 & 1 & $\underline{\mathbf{6}}$ & 4 & 1 & 0 & $\underline{\mathbf{6}}$ & 5 & 1 & 1 & 4 & 5 & 6 \\
\hline
\end{tabular}




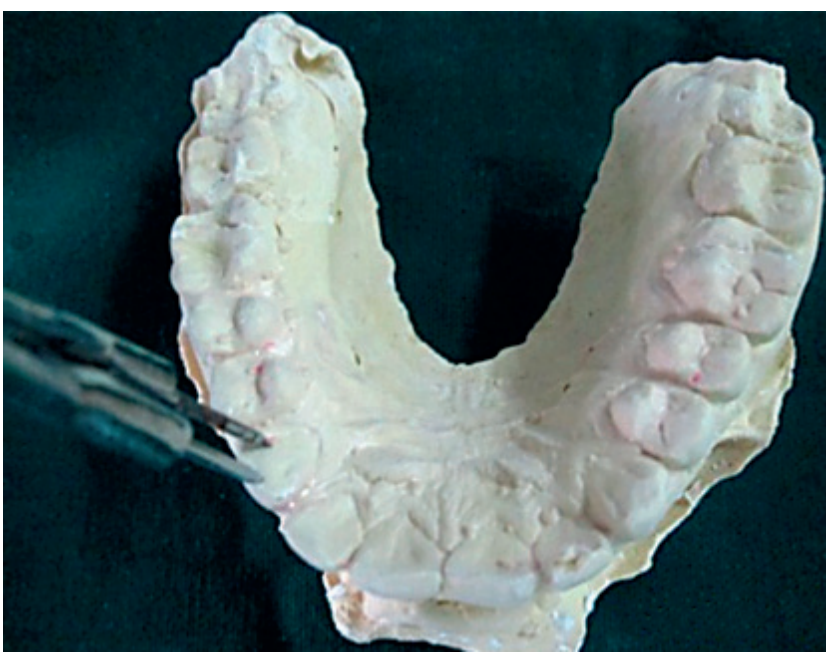

Figure 1: Point-like wear facet less than $1 \mathrm{~mm}$ in diameter

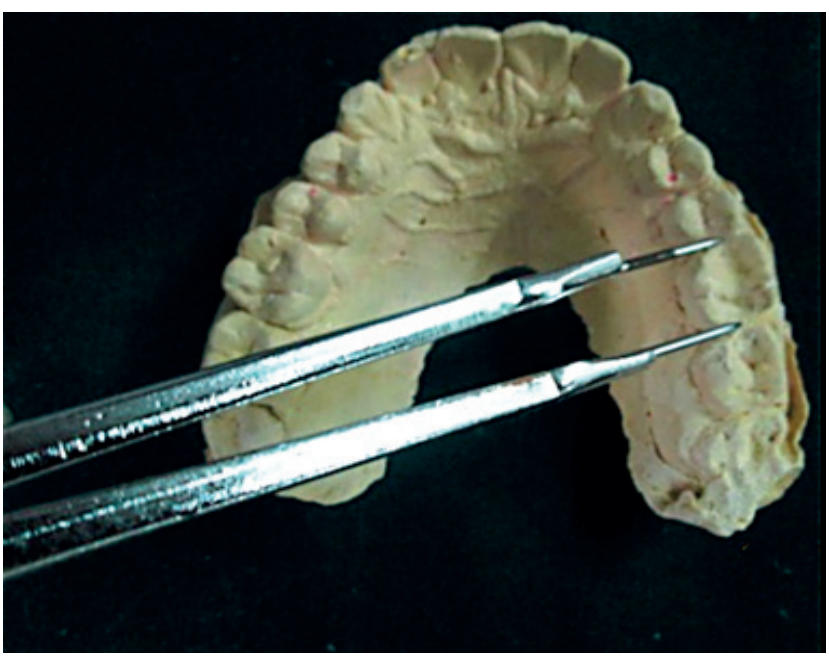

Figure 2: Linear wear facet less than $1 \mathrm{~mm}$ in width.

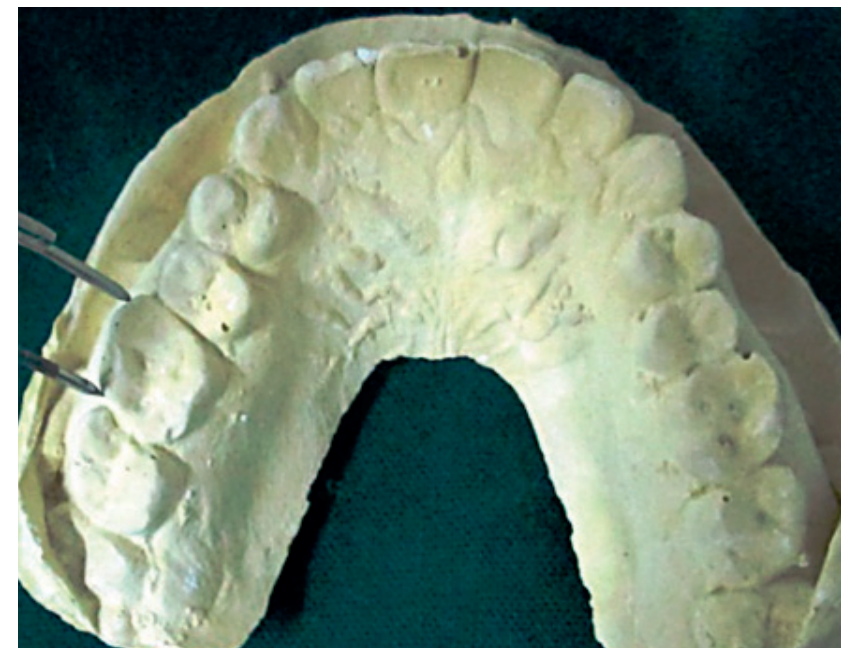

Figure3: Surface-like wear facet more than $1 \mathrm{~mm}$ in diameter

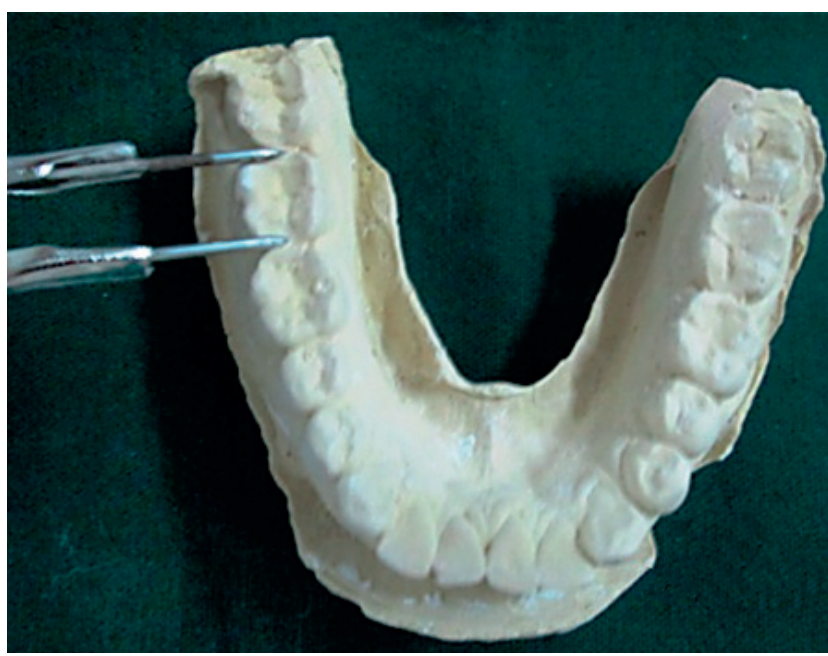

Figure 4: Band-like wear facet more than a $1 \mathrm{~mm}$ in width

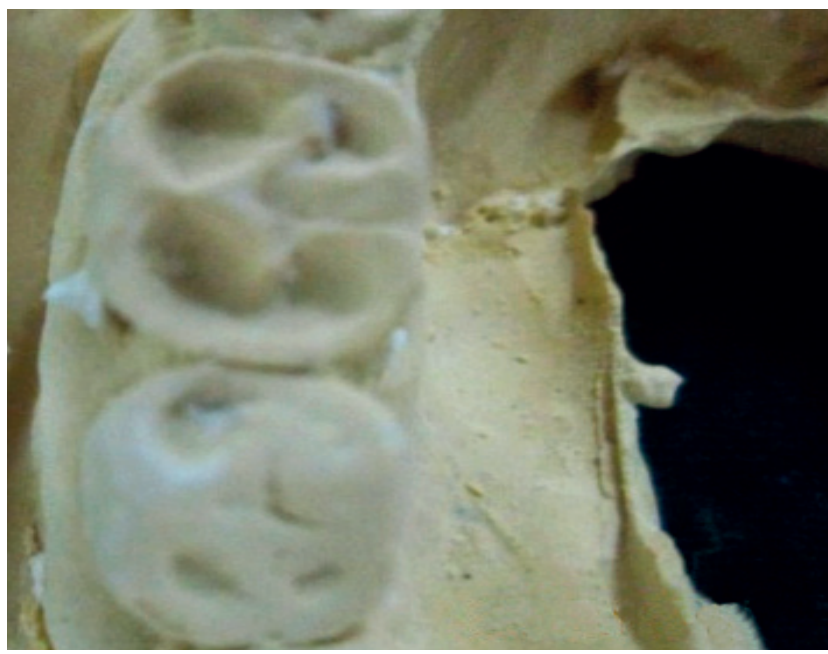

Figure 5: Concavity indicating the wear of dentin

\section{DISCUSSION}

As each day passes in life, human becomes ol der and older showing many regressive changes, but many of the people don't even know their exact age. So in certain instances like identifying a person in forensic cases, judicial punishments, age based eligibilities for job purposes age evidence may be demanded. ${ }^{7}$ Among the most reliable tools in the process of identity of age, teeth is one of them. ${ }^{10}$

Teeth known to be the hardest structures of the body can be preserved for longer periods of time and in mass disasters, it is teeth that are least affected and most durable than any other body parts. This explains the usage of teeth as frequently used tools in age estimation. ${ }^{4,7}$ 
Table 3: Mean values and standard deviations of tooth wear score for each tooth and levels of statistical significance between tooth wear scores of males and females

\begin{tabular}{|c|c|c|c|c|}
\hline \multirow{2}{*}{$\begin{array}{c}\text { TOOTH } \\
\text { NUMBER }\end{array}$} & \multicolumn{2}{|c|}{ MALES } & \multicolumn{2}{|c|}{ MALES } \\
\hline & MEAN & S.D. & MEAN & S.D. \\
\hline 14 & 0.72 & 0.456 & 0.75 & 0.500 \\
\hline 15 & 0.69 & 0.655 & 0.67 & 0.717 \\
\hline 16 & 2.28 & 1.468 & 2.56 & 1.812 \\
\hline 17 & 3.44 & 2.945 & 3.36 & 2.870 \\
\hline 24 & 0.18 & 0.389 & 0.17 & 0.378 \\
\hline 25 & 0.33 & 0.737 & 0.44 & 0.877 \\
\hline 26 & 1.49 & 1.805 & 1.53 & 1.905 \\
\hline 27 & 1.92 & 1.628 & 1.64 & 1.477 \\
\hline 34 & 0.49 & 0.556 & 0.33 & 0.478 \\
\hline 35 & 1.28 & 1.849 & 1.0 & 1.373 \\
\hline 36 & 1.77 & 1.926 & 2.3 & 2.068 \\
\hline 37 & 0.95 & 0.605 & 1.03 & 0.736 \\
\hline 44 & 0.82 & 0.790 & 0.75 & 0.806 \\
\hline 45 & 0.08 & 0.270 & 0.08 & 0.208 \\
\hline 46 & 2.54 & 2.594 & 2.19 & 2.136 \\
\hline 47 & 4.44 & 2.989 & 3.89 & 2.926 \\
\hline
\end{tabular}

Table 4: Regression analysis of age against tooth wear score for each tooth.

\begin{tabular}{cccc}
$\begin{array}{c}\text { TOOTH } \\
\text { NUMBER }\end{array}$ & $\mathbf{a}$ & $\mathbf{b}$ & $\mathbf{r}^{\mathbf{2}}$ \\
\hline 14 & 32.412 & 8.620 & 0.124 \\
\hline 15 & 29.488 & 13.596 & 0.635 \\
\hline 16 & 29.877 & 3.670 & 0.267 \\
\hline 17 & 27.890 & 3.189 & 0.630 \\
\hline 24 & 38.00 & 4.231 & 0.019 \\
\hline 25 & 36.624 & 5.456 & 0.143 \\
\hline 26 & 33.048 & 3.773 & 0.358 \\
\hline 27 & 33.424 & 2.972 & 0.158 \\
\hline 34 & 36.291 & 5.908 & 0.071 \\
\hline 35 & 34.679 & 3.536 & 0.247 \\
\hline 36 & 31.977 & 3.333 & 0.329 \\
\hline 37 & 30.247 & 8.601 & 0.244 \\
\hline 44 & 31.392 & 9.332 & 0.406 \\
\hline 45 & 38.594 & 1.739 & 0.002 \\
\hline 46 & 30.995 & 3.261 & 0.445 \\
\hline 47 & 24.490 & 3.413 & 0.752 \\
\hline
\end{tabular}

In past populations tooth wear was ubiquitous, intense and progressed rapidly. Also affected the occlusal surfaces and profoundly changed the occlusal plane. These observations when compared with the fact that food has become more refined over time as have the associated technologies and this means that such physiological and ontogenic occlusal evolution is now virtually impossible. Tooth wear that had remained unchanged since the origin of humanity have undergone profound changes in a 
very short space of time. ${ }^{6}$ Occlusal wear correlates the age of an individual as this fact is due to the consistent rate with which teeth erupt.

According to Kim's scoring system, degree of occlusal tooth wear is a method to assess age of an individual. Age estimated should be as accurate as possible since it narrows down the search enabling more efficient and time saving approach. ${ }^{8}$

Kim et al. devel oped a system of age estimation based on the degree of occlusal wear of premolars and molars. Results of estimated age were within \pm 3 years in $42.4 \%$ of males and $49.4 \%$ of females, within \pm 5 years in $61.8 \%$ of males and $63.3 \%$ o females. ${ }^{9}$

Yun et al. repeated further Kim's scoring system with an excellent reliability and occlusal tooth wear of a positive correlation with age. Estimated age results were \pm 5 years of actual ages in male and female subjects.

There have been a number of reports in the field of forensic odontology which have dealt estimating the chronological age in humans, living or dead. Typically, this research has approached age estimation in adults based on the degree of occlusal wear and dentin exposure without involving any invasive procedures resulting in high level of accuracy. Determination of occlusal wear differences in males and females was done that resulted increased tooth wear in males compared to females as agreed also by Seligman DA et al. ${ }^{11}$

It is well known that masticatory muscles in males are better developed than females thereby exerting stronger bite force resulting in increased tooth wear in males compared to females. It is obvious that as age increases, exposure of teeth to various regressive changes increases by which there is wear of teeth.

The method of scoring examined in previous studies showed a mean age difference between the actual and estimated of 3 years but here in the present study the calculated age was within \pm 1.52 years signifying the high level of accuracy. This suggests the reliability of occulsal wear based on Kim's scoring and its significance as an age determinant.

\section{CONCLUSSION}

Amongst the various age estimation procedures in forensic odontology, Kim's scoring system is one of the simple and reliable method. I ts applicability to wide age and non-invasive procedure makes it more preferable.

\section{REFERENCES}

1. Manjunath K, Saraswathi TR, Sriram G, Sivapathasundharam B, Porchelvam S. Reliability of automated biometrics in the analysis of enamel rod patterns. J Forensic Dent Sci 2009; 1(1):32-36.

2. Pratibha Rani RM, Mahima VG, Karthikeya Patil. Buccolinual dimension of teeth - An aid in sex determination. J Forensic Dent Sci 2009; 1(2):88-92.

3. Mesotten K, Gunst K, Carbonez A, Willems G. Dental age estimation and third molars: a preliminary study. Forensic Sci International 2002; 129:110-115.

4. Deepu George Mathew, S Rajesh, Elizabeth Koshi, Lakshmi E Priya, Amal S Nair, Aparna Mohan. Adult forensic age estimation using mandibular first molar radiographs : A novel technique. J Forensic Dent Sci 2013; 5(1):56-59.

5. LC Richards, J A Kaidonis, GC Townsend. A model for the prediction of tooth wear in individuals. Aus Dent J 2003; 48(4):259-262.

6. Emmanuel d'Incau, Christine Couture, Bruno Maureille. Human tooth wear in the past and the present: Tribological mechanisms, scoring systems, dental and skeletal compensations. Archives of oral biology 2012; 57:214 - 229.

7. Vikrant Kasat, FR Karjodkar, Walter Vaz. Age estimation in 25-45 yrs old females by physical and radiological methods. J Forensic Dent Sci 2010;2(2):91-95.

8. Guy Willems. A review of the most commonly used dental age estimation techniques. J Forensic Odontostom 2001;19:9-17

9. Young-ku Kim Young-Ku Kim, Hong-Seop Kho, KyoungHo Lee. Age estimation by occlusal tooth wear. J Forensic Sci 2000; 45(2):303-309.

10. Nishant Singh, Neeraj Grover, Navin Puri, Sanjeet Singh, Swati Arora. Age estimation from physiological changes of teeth: A reliable age marker ?. J Forensic Dent Sci 2014; 6(2): 113-121.

11. Seligman DA et al. The prevalence of dental attrition and its association with factors of age, gender, occlusion, and TMJ symptomatology. J Dent Res. 1988; 67:1323-1333.

12. F. Lobbezoo, W. J. Groenink, A. A. Kranendonk, I. H Aartman, M. Naeije. A reliability study of clinical occlusal tooth wear measurements. J Oral Rehab 2002; 29:872-889.

13. Smith BG et al. The prevalence of tooth wear in 1007 dental patients. J Oral Rehabil 1996; 23:232-239.

14. Donachie MA., Walls AWG. The tooth wear index: a flawed epidemiological tool in an ageing population group. Community Dent Oral Epidemol 1996; 24:152.

Shafer WG, Hine MK, Levy BM. Textbook of Oral Pathology. $6^{\text {th }}$ Ed. Noida: Elsevier publication. 2009:39-42. 